\title{
Effectiveness and Safety of an Endothelial Protector Drug, Aminapthone, In Patients with Idiopathic Tinnitus
}

\author{
M Negri, MP Alberici* and S Tassi \\ ENT Unit, Surgical Department of AUSL Modena, B Ramazzini Hospital, Carpi (MO), Italy
}

*Corresponding author: MP Alberici, ENT Unit, Surgical Department of AUSL Modena, B Ramazzini Hospital, Carpi (MO), ıary

\begin{tabular}{l}
\hline ARTICLE INFO \\
\hline Received: 幽 October 24, 2020 \\
Published: 幽 November 04, 2020
\end{tabular}

Citation: M Negri, MP Alberici, S Tassi. Effectiveness and Safety of an Endothelial Protector Drug, Aminapthone, In Patients with Idiopathic Tinnitus. Biomed J Sci \& Tech Res 31(4)-2020. BJSTR. MS.ID.005135.

Keywords: Aminapthone; Idiopathic Tinnitus; Endothelial Protector Drug; Quality of Life; Microcirculatory Disorders; THI

\section{ABSTRACT}

Background: This pilot study aimed to evaluate the feasibility effectiveness and safety of an endothelial protector drug, such as Aminapthone, for patients with chronic idiopathic tinnitus.

Methods: 16 consecutive out-patients afferent to our ENT Unit from May 2017 to June 2018 and affected by chronic idiopathic tinnitus and hearing loss were enrolled in this pilot study. All the included patients presented tinnitus that worsened their Quality of Life (QoL) from more than 6 months. All the patients presented hearing loss and performed vestibular-evoked potentials and a Skull Nuclear Magnetic Resonance to avoid central causes of hearing loss/tinnitus. AMINAPTHONE (75 mg cps bid) has been administered for six months and at baseline (T0) after 3 months (T1) and after 6 months (T3) have been evaluated audiometric parameters together with a Tinnitus Handicap Inventory (TIH) scales. All the patients continued their standard of care during AMINAPTHONE treatment. The primary end point was the regression or the non-worsening of THI during the $3-6$ months of the observational period according to the audiometric parameters, the secondary end point was the compliance to drug treatment and the drop-out of patients from the protocol study.

Results: After 3 months of treatment the medium score of THI was statistically significant decrease from 34.37 to 27.81 ( $p=0.027$ ) while after 6 months (T2) THI was 30.75 with a non-statistically significant decrease between T0 and T2 (p = 0.107). Surprisingly all the patients concluded the six months treatment period confirming the good compliance to the test treatment. In addition, no adverse effects related to the treatment were recorded in the 16 patients enrolled. Conclusions: The results of this pilot observational study seem to confirm the approach with an endothelial protector drug, such as AMINAPTHONE, in the treatment of Idiopathic Tinnitus. The improvement of THI together with the good domiciliary compliance to the test treatment seems to support "the microcirculatory etiopathogenesis" of the subjective idiopathic tinnitus.

\section{Introduction}

Subjective Idiopathic Tinnitus is a common and disturbing condition characterized by an auditory perception of sound or noise that has no external source [1,2]. Almost $5 \%$ to $10 \%$ of people suffer from such condition (3-5 di 1) and this rate could increase up to $30 \%$ among the elderly [3]. Tinnitus very often becomes a "chronic condition" and may result in depression, anxiety, insomnia and, especially, "poor Quality of Life (QoL) in patients with such symptom. Currently no highly effective management therapy was recommended for Tinnitus despite a lot of treatments have been tried to control this condition. Microcirculatory disorders of the inner ear with a hemodynamic and metabolic imbalance of the endothelial leading to a damage of the cochlear cells, are often bring into play in the classical cochleovestibular symptoms such as tinnitus [4]. From the literatures seems to be clear the relationship between inner ear microcirculation dearrangements and Tinnitus: this is the reason why we try to use "an endothelial protector drug" 
such as AMINAPTHONE ${ }^{\mathrm{TM}}$, that has recently demonstrated to be effective in down-regulates molecules with key vasoactive roles such as E-Selectine and Endothelin 1 (ET-1) expression in vitro and in vivo [5-7] and to modulate the expression of endothelial inflammatory molecules that contribute to pathogenesis of several conditions where the endothelial dysfunction may play the main role, in particular in early events $[8,9]$.

\section{Materials and Methods}

We have retrospectively analyzed data of sixteen patients (medium age $61.87+/-13.68$ years, 9 women and 7 men), affected by idiopathic chronic tinnitus afferent to ENT Unit of Ramazzini Hospital in Carpi (Modena) from May 2017 to June 2018. Table 1 shows the main characteristics of the patients. All the patients enrolled in this observational study aged more than 18 years, presented Tinnitus from minimum six months that worsened their Quality of Life (QoL) together with hearing loss. They performed vestibular evoked potentials and Skull Nuclear Magnetic Resonance to avoid central causes of hearing loss/Tinnitus. All the patients add to their standard of care AMINAPTHONE (75 mg cps bid) for 6 months and were evaluated for audiometric parameters and for their subjective perception of Tinnitus by using the Tinnitus Handicap Inventory (THI) scale [10-12] at baseline (T0) after 3 months (T1) and after 6 months (T2) of treatment (Table 2). We exclude from the analysis patients with inflammatory ear pathology or retrocochlear neurologic or neurosurgery pathologies; all patients had already tried other therapy without significant benefits. We exclude also patients taking steroid-drugs or NSAIDs (nonsteroidal antiinflammatory drugs).

Table 1: Characteristics of the population: We enrolled 16 patients, 7 male and 9 females with tinnitus. Every patient has been tested with hearing measurement, Auditory Brainstem Response and Magnetic Resonance Imaging of head with Gadolinium.

\begin{tabular}{|c|c|c|c|c|c|c|c|c|c|}
\hline Patient & Age & Sex & PTA Right & PTA Left & $\begin{array}{c}\text { Changing } \\
\text { PTA }\end{array}$ & $\begin{array}{c}\text { Tinnitus } \\
\text { Site }\end{array}$ & $\begin{array}{c}\text { Characteristic of } \\
\text { tinnitus (T0) }\end{array}$ & $\begin{array}{c}\text { Characteristic of } \\
\text { tinnitus (T1) }\end{array}$ & $\begin{array}{c}\text { Characteristic of } \\
\text { tinnitus (T2) }\end{array}$ \\
\hline 1 & 66 & M & $20 \mathrm{~dB}$ & $20 \mathrm{~dB}$ & NO & left & $1500 \mathrm{~Hz} / 55 \mathrm{~dB}$ & $2000 \mathrm{~Hz} / 45 \mathrm{~dB}$ & $3000 \mathrm{~Hz} / 50 \mathrm{~dB}$ \\
\hline 2 & 48 & M & $10 \mathrm{~dB}$ & $25 \mathrm{~dB}$ & NO & left & $1000 \mathrm{~Hz} / 35 \mathrm{~dB}$ & $3000 \mathrm{~Hz} / 25 \mathrm{~dB}$ & $125 \mathrm{~Hz} / 25 \mathrm{~dB}$ \\
\hline 3 & 70 & M & $65 \mathrm{~dB}$ & $30 \mathrm{~dB}$ & NO & Right & $2000 \mathrm{~Hz} / 75 \mathrm{~dB}$ & $2000 \mathrm{~Hz} / 80 \mathrm{~dB}$ & $6000 \mathrm{~Hz} / 90 \mathrm{~dB}$ \\
\hline 4 & 46 & F & $25 \mathrm{~dB}$ & $30 \mathrm{~dB}$ & NO & Left (bil) & $8000 \mathrm{~Hz} / 65 \mathrm{~dB}$ & $4000 \mathrm{~Hz} / 70 \mathrm{~dB}$ & $4000 \mathrm{~Hz} / 60 \mathrm{~dB}$ \\
\hline 5 & 41 & F & $20 \mathrm{~dB}$ & $20 \mathrm{~dB}$ & NO & right & $250 \mathrm{~Hz} / 10 \mathrm{~dB}$ & $250 \mathrm{~Hz} / 15 \mathrm{~dB}$ & $750 \mathrm{~Hz} / 25 \mathrm{~dB}$ \\
\hline 6 & 86 & M & $25 \mathrm{~dB}$ & $30 \mathrm{~dB}$ & NO & right & $125 \mathrm{~Hz} / 30 \mathrm{~dB}$ & $125 \mathrm{~Hz} / 25 \mathrm{~dB}$ & $125 \mathrm{~Hz} / 20 \mathrm{~dB}$ \\
\hline 7 & 55 & M & $25 \mathrm{~dB}$ & $25 \mathrm{~dB}$ & NO & Right (bil) & $8000 \mathrm{~Hz} / 35 \mathrm{~dB}$ & $8000 \mathrm{~Hz} / 40 \mathrm{~dB}$ & $8000 \mathrm{~Hz} / 50 \mathrm{~dB}$ \\
\hline 8 & 46 & F & $20 \mathrm{~dB}$ & $20 \mathrm{~dB}$ & NO & Left (bil) & $2000 \mathrm{~Hz} / 30 \mathrm{~dB}$ & $6000 \mathrm{~Hz} / 60 \mathrm{~dB}$ & $6000 \mathrm{~Hz} / 50 \mathrm{~dB}$ \\
\hline 9 & 74 & F & $40 \mathrm{~dB}$ & $40 \mathrm{~dB}$ & NO & Right & $125 \mathrm{~Hz} / 20 \mathrm{~dB}$ & $3000 / 75 \mathrm{~dB}$ & $250 \mathrm{~Hz} / 20 \mathrm{~dB}$ \\
\hline 10 & 58 & F & $30 \mathrm{~dB}$ & $20 \mathrm{~dB}$ & NO & Right & $8000 \mathrm{~Hz} / 55 \mathrm{~dB}$ & $8000 \mathrm{~Hz} / 65 \mathrm{~dB}$ & $8000 \mathrm{~Hz} / 55 \mathrm{~dB}$ \\
\hline 11 & 62 & F & $20 \mathrm{~dB}$ & $15 \mathrm{~dB}$ & NO & Left & $4000 \mathrm{~Hz} / 35 \mathrm{~dB}$ & $1500 \mathrm{~Hz} / 25 \mathrm{~dB}$ & $3000 \mathrm{~Hz} / 30 \mathrm{~dB}$ \\
\hline 12 & 46 & M & $40 \mathrm{~dB}$ & $30 \mathrm{~dB}$ & NO & Right (bil) & $1000 \mathrm{~Hz} / 30 \mathrm{~dB}$ & $8000 \mathrm{~Hz} / 65 \mathrm{~dB}$ & $6000 \mathrm{~Hz} / 45 \mathrm{~dB}$ \\
\hline 13 & 74 & F & $75 \mathrm{~dB}$ & $40 \mathrm{~dB}$ & NO & Right & $1000 \mathrm{~Hz} / 50 \mathrm{~dB}$ & $2000 \mathrm{~Hz} / 65 \mathrm{~dB}$ & $2000 \mathrm{~Hz} / 70 \mathrm{~dB}$ \\
\hline 14 & 77 & M & $40 \mathrm{~dB}$ & $65 \mathrm{~dB}$ & NO & Left & $125 \mathrm{~Hz} / 50 \mathrm{~dB}$ & $125 \mathrm{~Hz} / 70 \mathrm{~dB}$ & $750 \mathrm{~Hz} / 35 \mathrm{~dB}$ \\
\hline 15 & 67 & F & $15 \mathrm{~dB}$ & $40 \mathrm{~dB}$ & NO & Left (bil) & $750 \mathrm{~Hz} / 40 \mathrm{~dB}$ & $750 \mathrm{~Hz} / 35 \mathrm{~dB}$ & - \\
\hline 16 & 74 & F & $25 \mathrm{~dB}$ & $25 \mathrm{~dB}$ & NO & Right & $4000 \mathrm{~Hz} / 70 \mathrm{~dB}$ & $4000 \mathrm{~Hz} / 65 \mathrm{~dB}$ & $4000 \mathrm{~Hz} / 60 \mathrm{~dB}$ \\
\hline
\end{tabular}

Note: *Legend: PTA: pure tone audiometry is the medium value in $250-500-1000-2000-4000 \mathrm{~Hz}$ and is expressed in dB; Changing PTA: if hearing threshold medium levels changes during this six-months study; we consider a changing if there is a difference more than 10dB; Tinnitus site: the ear in which patient refers tinnitus; when patient refers bilateral (bil), we indicated the worst side. Characteristic of tinnitus: we indicated characterizes of tinnitus in frequency $(\mathrm{Hz})$ and intensity $(\mathrm{dB})$.

Table 2: Tinnitus Handicap Inventory Grades and their corresponding scores (13).

\begin{tabular}{|c|c|c|}
\hline Grade & Score & Handicap \\
\hline 1 & $0-16$ & Slight or no handicap \\
\hline 2 & $18-36$ & Mild handicap \\
\hline 3 & $38-56$ & Moderate handicap \\
\hline 4 & $58-76$ & Severe handicap \\
\hline 5 & $78-100$ & catastrophic handicapores (13). \\
\hline
\end{tabular}


Considering the hearing loss of all the patients and the chronicity of their pathologies an improvement in their QoL relate to subjective TINNITUS measured by THI scale at $3^{\text {rd }}$ or $6^{\text {th }}$ months was considered as primary end point. Secondary end-points was considered the "compliance of the patients" to the study drug together with the number of "drop-out patients" during the $6^{\text {th }}$ months of treatment. A study of the "intra-patient" THI values, according to the audiometric parameters, was also performed in order to detect the correlation between a possible worsening of the audiometric parameters due to the natural course of the chronical pathology and THI values improvement/impairments.

The outcome values were conducted by using SAS package 8.1 (SAS Institute Inc, Cary, NC, USA): differences in demographic and clinical variable were evaluated by using T-Test in the cae of continuous variables. A p value of $<0.05$ was considered as statistically significant. All patients gave informed, signed consent to participate in this study.

\section{Results}

All the 16 patients enrolled in this observational retrospective study complete the 6-month study period. No one patients presented adverse effects related to the study drug during the same time. Table 3 shown the results for single patient related to the TINNITUS- Quality of Life (THI). THI mean value at T0 (baseline) was $34.37+/-17.83$ while the same value significantly decreases to $27.81+/-15.44)(p<0.03)$ after three months of treatment (Figure 1). After 6 months of treatment (T2) THI mean value was $30.75+/-$ 17.58 with a non-statistically significant $p$-value decrease $(p=0.11)$ versus T0 $($ THI mean value $=34.37+/-17.83$ ) (Figure 2 ).

Table 3: Patients THI value.

\begin{tabular}{|c|c|c|c|}
\hline Patient & T0 & T1 & T2 \\
\hline 1 & 30 & 32 & 32 \\
\hline 2 & 62 & 50 & 52 \\
\hline 3 & 2 & 10 & 6 \\
\hline 4 & 26 & 26 & 12 \\
\hline 5 & 8 & 4 & 4 \\
\hline 6 & 20 & 24 & 28 \\
\hline 7 & 40 & 12 & 28 \\
\hline 8 & 36 & 14 & 18 \\
\hline 9 & 46 & 24 & 42 \\
\hline 10 & 36 & 30 & 28 \\
\hline 11 & 14 & 16 & 14 \\
\hline 12 & 66 & 56 & 54 \\
\hline 13 & 48 & 46 & 56 \\
\hline 14 & 32 & 35 & 24 \\
\hline 15 & 36 & 20 & 38 \\
\hline 16 & 2 & 10 & 6 \\
\hline
\end{tabular}

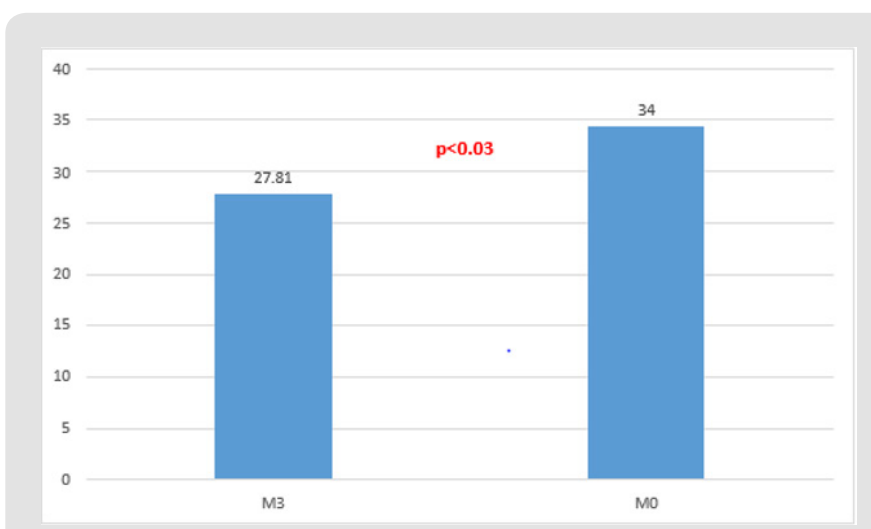

Figure 1.

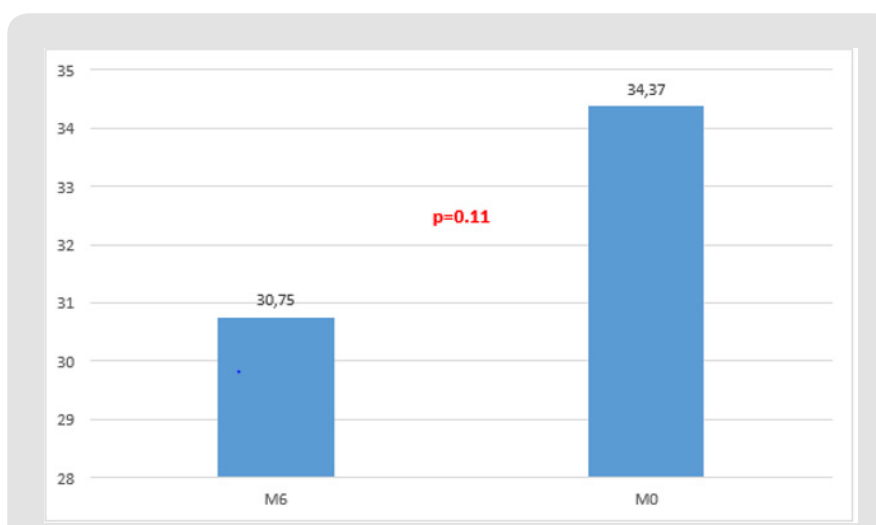

Figure 2.

Referring to the secondary end-points (drop-out of the patients from the study during the sixth months of treatment and patient's compliance to treatment) all patients follow the six months courses of the Aminapthone treatment without adverse effects and with a good compliance to treatment: considering the kind of patients who always research a resolutive and immediately tinnitus treatment after have tried many other pharmaceutical an non treatment and the "usually loosing patients during a long- time treatment" we can conclude that Aminapthone treatment was "well-tolerated" (or well-accepted) from patients with a "good personal satisfactory index" for Aminapthone treatment and that, consequently, we have reach the secondary end-point of the study [13].

\section{Discussion}

Tinnitus is one of the most common hearing disorders; many risk factors has been individualized for this "stressing condition" such as age, hearing loss, inflammatory diseases or tumors of the ear, head or vertebral cervical trauma, ototoxic drugs, noise exposure and psychological disorders. Tinnitus could be a life-long disorder bringing to anxiety, depression, insomnia, hyperacusis, concentration difficulties and, sometimes, to suicide. QoL of people affecting by Tinnitus is often worsened leading to transform this hearing disorder in a "very serious disorder" involving "all the 
personal activity's area" of the patient. The inner ear diseases are often caused by microcirculatory disorders [14].

Figuerado and Coll, reviewing the association between arterial hypertension and Tinnitus conclude that "there is evidence of an association between Tinnitus and Hypertension "and that "changes in the cochlear microcirculation, resulting in hearing loss, may be an adjuvant factor in Tinnitus pathophysiology" [15]. Evidence of literatures suggest that restore hemodynamic and dysmetabolic imbalance responsible for cochleovestibular microcirculatory disorders could represent a therapeutic strategy to control primary idiopathic Tinnitus. Considering that phenomenon such as secretions of endothelial pro-inflammatory molecules, hyperexpression of Vascular Cells Adhesion Molecules (VCAM) and Endothelial Leukocytes Adhesion Molecules (ELAM) and hyperexpression of Endothelin 1 (ET-1), seems to be "the key player" in the microcirculatory disorders.

The use of an endothelial protector drug such as AMINAPTHONE $^{\text {TM }}$ [16] could represent a new and interesting pharmacological approach in the "multidisciplinary treatment" of Primary Idiopathic Tinnitus. The results of this retrospective, observational study performed on 16 outpatients affected by Chronic Idiopathic Tinnitus seems to confirm this "endothelial protector approach". QoL of Tinnitus patients measured by THI significantly improves $(p=0.03)$ immediately after 3 months of treatment and this improvement was confirmed, also if a non-statistically significant manner, after 6 months $(p=0.11)$. Interestingly, in the only 6 patients in which there were a deterioration of the THI at 6 months, we have observed a worsened in the audiometric performance: probably "the worsening of idiopathic chronic hearing loss pathology" was too strong to allow to endothelial protection to control Tinnitus. Nevertheless, the primary end-point of this observational study (THI improvement) has been significantly achieved after 3 months of treatment with AMINAPTHONE; probably an "plateau- effect" do not permit to obtain a statistically significative improvement after 6 months of treatment, but in all cases, there were no regression-effect.

At the same time the study secondary end-point has been completely achieved because no one patient stop to keep the study drug and the compliance of the patient to the six months study treatment was good in the $100 \%$ of the patients. This was a very interesting observation especial if confronted with our previous experience: the use of a new drug in patient affected by Tinnitus was immediately stopped in a lot of patients because of the "stress conditions" of the same patients. Obviously this study has a lot of methodological limitations such as the design of the study, the little number of patients enrolled in the trial, the retrospective- observational methodology, together with the open and retrospective protocol design so that every observational results must be interpreted with caution. In future a prospective, controlled, double blind clinic study may confirm these preliminary and pivotal results.

In conclusion, there is an association between TINNITUS and microcirculatory disorders. This association cannot be dissociated from the hearing loss, which was also more prevalent among Tinnitus patients. The use of drugs able to protect the endothelium damages has not been very well tested. Aminapthone is the first drug of a new drug's category: "the endothelial-protector drugs". The preliminary and pilot results of this observational study seem to encourage the use of this new pharmacological treatment in terms of Qol improvement of patients and of patients' compliance to treatment. In future a prospective, controlled, randomized, double blind clinic study may confirm these preliminary but interesting results.

\section{References}

1. Tamir SO, Marom T, Shushan S (2018) Tinnitus Perspectives among Israeli Ear, Nose and Throat Physicians: A Nationwide Survey. J Int Adv Otol 14(3): 437-442.

2. Bhatt JM, Lin HW, Bhattacharyya N (2016) Prevalence, Severity, Exposures, and Treatment Patterns of Tinnitus in the United States. JAMA Otolaryngol Head Neck Surg 142(10): 959-965.

3. Lasisi AO, Abiona T, Gureje O (2010) Tinnitus in the elderly: Profile, correlates, and impact in the Nigerian Study of Ageing. Otolaryngol Head Neck Surg 143(4): 510-515.

4. Neri S, Signorelli S, Pulvirenti D, Agostino Serra, Alkaterini Tsami, et al. (2006) Oxidative stress, nitric oxide, endothelial dysfunction and tinnitus. Free Radic Res 40(6): 615-618.

5. Lenna S (2006) Novel mode of action of the aminaphtone: downregulation of a E-Selectine expression in ECV- 304 cells. Int Angiology 25: 189.

6. Scorza R, Santaniello A, Salazar G, Karen Toussoun, Lorenzo Beretta, et al. (2008) Effects of aminaftone $75 \mathrm{mg}$ TID on soluble adhesionmolecules: a 12- week, randomized, open-label pilot study in patients with systemic sclerosis. Clin Ther 30(5): 924-929.

7. Scorza R, Santaniello A, Salazar G (2008) Aminaftone, a derivative of 4-aminobenzoic acid, downregulates endothelin-1 production in ECV304 Cells: an in vitro Study. Drugs R D 9(4): 251-257.

8. Salazar G, Bellocchi C, Todoerti K (2016) Gene expression profiling reveals novel protective effects of Aminaphtone on ECV304 endothelial cells. Eur J Pharmacol 782: 59-69.

9. Salazar G, Bellocchi C, Todoerti K, Luca Piacentini, Raffaella Scorza, et al. (2016) Time-course gene expression data on the transcriptional effects of Aminaphtone on ECV304 endothelial cells. Data Brief 8: 836-8350.

10. Newman CW, Jacobson GP, Spitzer JB (1996) Development of the Tinnitus Handicap Inventory. Arch Otolaryngol Head Neck Surg 122(2): 143-148

11. Moschen R, Fioretti A, Eibenstein A, Eleonora Natalini, Domenico Cuda, et al. (2018) Validation of the Italian Tinnitus Questionnaire Short Form (TQ 12- I) as a Brief Test for the Assessment of Tinnitus-Related Distress: Results of a Cross-Sectional Multicenter- Study. Front Psychol 9: 65.

12. Monzani D, Genovese E, Marrara A (2008) Validity of the Italian adaptation of the Tinnitus Handicap Inventory; focus on quality of life and psychological distress in tinnitus-sufferers. Acta Otorhinolaryngol Ital 28(3): 126-134

13. Neri G (2018) Sulodexide nell'acufene soggettivo idiopatico: Update 3009-2018. OTO Neurologia 49: 17-21. 
14. Neri G, Marcelli V, Califano L (2018) Glicover Investigators. Assessment of the effect of mesoglycan in the treatment of audiovestibular disorders of vascular origin. Int J Immunopathol Pharmacol.

15. Figueiredo RR, de Azevedo AA, Penido Nde O (2015) Tinnitus and arterial hypertension: a systematic review. Eur Arch Otorhinolaryngol 272(11): 3089-3094

\section{ISSN: 2574-1241}

DOI: 10.26717/BJSTR.2020.31.005135

MP Alberici. Biomed J Sci \& Tech Res

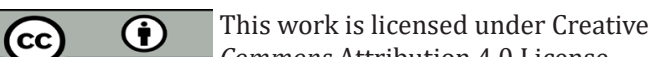

Submission Link: https://biomedres.us/submit-manuscript.php
16. Bertini M, Battista Gervasi G, Baldacci M (2017) Aminapthone: a drug for microcirculation de-arrangement: novel aspects of an endothelial protector drug. ESM-EVBO 2017. $2^{\text {nd }}$ Joint Meeting of the European Society for Microcirculation (ESM) and European Vascular Biology Organisation (EVBO). Geneva, Switzerland, 29 May to 1 June 2017: Abstracts. J Vasc Res:44: 6C-04.

$\begin{array}{ll}\text { BIOMEDICAL } & \text { Assets of Publishing with us } \\ \text { RESEARCHES } & \text { - Global archiving of articles } \\ \text { - Immediate, unrestricted online access }\end{array}$

